\title{
Predictors of Mortality for Patients with COVID-19 in the Rural Appalachian Region
}

\author{
Huzefa Bhopalwala (D)', Nakeya Dewaswala², Sandhya Kolagatla', Lauren Wisnieski ${ }^{3}$, Jonathan Piercy', \\ Adnan Bhopalwala', Nagabhishek Moka' \\ 'Department of Internal Medicine, Appalachian Regional Healthcare, Whitesburg, KY, USA; ${ }^{2}$ Department of Cardiovascular Disease, University of \\ Kentucky, Lexington, KY, USA; ${ }^{3}$ Department of Public Health and Research, Lincoln Memorial University, Harrogate, TN, USA \\ Correspondence: Nakeya Dewaswala, Department of Cardiovascular Disease, University of Kentucky, 900 South Limestone Street, Charles \\ T. Wethington Building Rm. 326, Lexington, KY, 40536-0200, USA, Tel +I 4252I3640I, Email nakeya52@gmail.com
}

Background: The prevalence and outcome of coronavirus disease 2019 (COVID-19) in rural areas is unknown.

Methods: This is a multi-center retrospective cohort study of hospitalized patients diagnosed with COVID-19 from April 5, 2020 to December 31, 2020. The data were extracted from 13 facilities in the Appalachian Regional Healthcare system that share the same electronic health record using ICD-10-CM codes.

Results: The number of patients diagnosed with COVID-19 per facility ranged from 5 to 535 with a median of 106 patients. Total mortality was $11.4 \%$ and ranged from $0 \%$ to $22.6 \%$ by facility (median: $9.0 \%$ ). Non-survivors had a greater prevalence of congestive heart failure (CHF), hypertension, type 2 diabetes mellitus, stroke, transient ischemic attack (TIA), and pulmonary embolism. Patients who died were also more likely to have had chronic obstructive pulmonary disease (COPD), acute respiratory failure (ARF), liver cirrhosis, chronic kidney disease (CKD), dementia, cancer, anemia, and opiate dependence.

Conclusion: The aging population, multiple co-morbidities, and health-related behaviors make rural patients vulnerable to COVID-19. A better understanding of the disease in rural areas is crucial, given its heightened vulnerability to adverse outcomes.

Keywords: coronavirus, COVID-19, SARS-CoV-2, cohort, mortality, survival

\section{Introduction}

The coronavirus disease 2019 (COVID-19) pandemic has affected over 238 million individuals and caused over 4 million deaths worldwide as of October, 2021. ${ }^{1}$ As the disease spreads, there has been growing recognition that people in rural communities may be disproportionately affected. The negative consequences of health disparities for rural communities in the United States were an issue before the pandemic. Rural communities have faced greater morbidity, mortality, and percentages of excess deaths from the five leading causes of death, including cancer and cardiovascular disease. ${ }^{2}$ This disparity has also been seen in various infectious diseases, such as hepatitis A, influenza, and HIV. ${ }^{3-5}$

There are a number of reasons why rural communities are at high risk. Compared to urban dwellers, rural residents are older, and more likely to have underlying health conditions. ${ }^{6}$ In addition, rural population have greater prevalence of coal workers' pneumoconiosis which may affect outcomes of COVID-19 in this subgroup. ${ }^{7,8}$ Patients in rural communities have limited access to emergency and intensive care healthcare facilities. ${ }^{9}$ Rural patients live farther away from health care facilities compared to urban dwellers. In addition, there is a shortage of health care providers in rural America. ${ }^{10}$ Initially, it was thought that the low population density reduction helps facilitate social distancing and isolation, which protects rural residents by reducing both the rate of exposure and contraction of the disease. ${ }^{11}$ However, in September 2020, COVID-19 incidence (cases per 100,000 population) in rural counties surpassed that in urban counties. ${ }^{12}$

The prevalence and outcome of COVID-19 in rural areas is unknown. The aim of this study is to describe the demographics, clinical characteristics, and outcomes of hospitalized adults with coronavirus disease 2019 (COVID-19) in a large healthcare system in rural Kentucky and West Virginia. 


\section{Methods}

This is a multi-center retrospective cohort study of hospitalized patients diagnosed with COVID-19 from April 5, 2020 to December 31, 2020. This study was approved by the Appalachian Regional Healthcare Institutional Review Board (IRB). As per IRB requirements, written consent was waived for this project as it is a retrospective study, which includes abstraction of data from medical records.

The data was extracted from 13 facilities in the Appalachian Regional Healthcare system that share the same electronic health record. The principals admitting diagnosis of COVID-19 using ICD-10-CM codes in patients 18 years or older were identified. The information for all patients, including demographic data, clinical characteristics, laboratory parameters, treatment data and outcomes, were extracted electronically. Patients with missing discharge disposition data were excluded. Manual individual chart review performed was not performed. Serum biomarkers were categorized as low/normal versus high based on reference levels in the literature. D-dimer was categorized as high if concentrations were 0.5 or greater. For CRP, high concentrations were defined as $3.0 \mathrm{mg} / \mathrm{L}$ or greater. For males and females, a high erythrocyte sedimentation rate was $>22 \mathrm{~mm} / \mathrm{hr}$ and $29 \mathrm{~mm} / \mathrm{hr}$, respectively. For males and females, a high ferritin was $>336 \mathrm{mg} / \mathrm{L}$ and $>307 \mathrm{mg} / \mathrm{L}$, respectively. An elevated LDH was defined as $\geq 280 \mathrm{U} / \mathrm{L}$. Levels of categorical variables with low cell counts were combined for statistical analysis purposes to ensure adequate sample size to estimate effects.

The primary outcome was in-hospital mortality. Secondary outcomes included 30-day and 60-day readmission rate, and the length of stay in the hospital.

\section{Data Analysis}

Descriptive statistics were used to summarize the continuous and categorical variables. The mean and standard error were used for the continuous variables and the categorical variables were expressed as percentages. Categorical variables were reported as absolute numbers and proportions, and compared using the chi-square or Fisher's exact test. Continuous variables were analyzed with independent $t$-tests. Analysis of variance (ANOVA) was used instead of t-tests for categorical variables with more than 2 categories. For all ANOVA models and t-tests, normality and equal variances were checked. If normality was violated, the offending variables were log transformed to achieve normality of the data. Models were adjusted for unequal variances as needed.

Biomarker data was only collected for a subset of patients, so two sets of models were built (with and without biomarker data) for each outcome of interest (mortality, readmittance within 30 days and between 31 and 60 days, and length of stay). Mixed effects logistic and linear regression models were built for binary and continuous outcomes, respectively. Only those that survived the first hospitalization were included in the readmission models. We used a backward selection procedure for variable selection and variables were retained if they reached statistical significance. For each model, random intercepts for facility and month were included, unless their estimates were negligible. Models were estimated using robust standard errors. Normality of random effects was tested for all models. The $\mathrm{P}$ value of $<0.05$ was considered statistically significant. All statistical analyses were performed using Stata 14.2 (StataCorp, College Station, TX).

\section{Results}

In total, data for 1628 patients was extracted and 2 patients were excluded due to missing discharge disposition data. BMI was missing in 69 observations and marital status was missing 26 observations. The number of patients per facility ranged from 5 to 535 with a median of 106 patients. Total mortality was $11.4 \%$ and ranged from $0 \%$ to $22.6 \%$ by facility (median: 9.0\%).

The differences in the baseline demographic characteristics, clinical characteristics, serum biomarkers, and treatments among patients who survived versus died in patients with COVID-19 pneumonia are shown in Table 1. Older patients had a higher mortality ( $20.2 \%$ in 74 years of age and older) compared to the younger patients $(0.8 \%$ in 18 to 39 years of age). Non-survivors had a greater prevalence of congestive heart failure (CHF), hypertension, type 2 diabetes mellitus, stroke, transient ischemic attack (TIA), and pulmonary embolism. Patients who died were also more likely to have had 
Table I Differences in Demographic Characteristics, Clinical Characteristics, Serum Biomarkers, and Treatments Among Patients Who Survived versus Died in a Sample of Patients Hospitalized for COVID-19

\begin{tabular}{|c|c|c|c|c|c|c|c|c|}
\hline & & \multicolumn{2}{|c|}{ Died $(n=185)$} & \multicolumn{2}{|c|}{ Survived $(n=|44|)$} & \multicolumn{2}{|c|}{ Total $(n=1626)$} & \multirow[t]{2}{*}{ p-value ${ }^{a}$} \\
\hline & & $\mathbf{n}$ & \% (Within Row) & $\mathbf{n}$ & \% (Within Row) & $\mathbf{n}$ & $\%$ (of Total) & \\
\hline \multirow[t]{5}{*}{ Age (years) } & 18 to 39 & I & 0.8 & 125 & 99.2 & 126 & 7.8 & $<0.01^{b}$ \\
\hline & 40 to 49 & 4 & 2.4 & 161 & 97.6 & 165 & 10.2 & - \\
\hline & 50 to 64 & 24 & 6.1 & 373 & 94 & 397 & 24.4 & - \\
\hline & 65 to 74 & 55 & 12.6 & 382 & 87.4 & 437 & 26.9 & - \\
\hline & 74 and older & 101 & 20.2 & 400 & 79.8 & 501 & 30.8 & - \\
\hline \multirow[t]{2}{*}{ Gender } & Male & 95 & 11.8 & 712 & 88.2 & 807 & 49.6 & 0.62 \\
\hline & Female & 90 & 11 & 729 & 89 & 819 & 50.4 & - \\
\hline \multirow[t]{5}{*}{ BMI } & $<18.5$ & 8 & 17 & 39 & 83 & 47 & 3 & $<0.0 \mathrm{I}^{\mathrm{b}}$ \\
\hline & $18.5-<25.0$ & 44 & 15.7 & 236 & 84.3 & 280 & 18 & - \\
\hline & $25.0-<30.0$ & 51 & 12.1 & 371 & 87.9 & 422 & 27.1 & - \\
\hline & $30.0-<35.0$ & 23 & 7.4 & 290 & 92.7 & 313 & 20.1 & - \\
\hline & 35 and greater & 46 & 9.3 & 449 & 90.7 & 495 & 31.8 & - \\
\hline \multirow[t]{5}{*}{ Marital status } & Married & 70 & 8.8 & 724 & 91.2 & 794 & 49.6 & $<0.001^{b}$ \\
\hline & Single & 31 & 9.8 & 284 & 90.2 & 315 & 19.7 & - \\
\hline & Divorced/ & 79 & 16.1 & 412 & 83.9 & 491 & 30.7 & - \\
\hline & Separated/ & & & & & & & \\
\hline & Widowed $^{e}$ & & & & & & & \\
\hline \multirow[t]{2}{*}{ ARF } & Yes & 143 & 21.3 & 530 & 78.8 & 673 & 41.4 & $<0.001$ \\
\hline & No & 42 & 4.4 & 911 & 95.6 & 953 & 58.6 & - \\
\hline \multirow[t]{2}{*}{ CKD } & Yes & 124 & 21.5 & 452 & 78.5 & 576 & 35.4 & $<0.001$ \\
\hline & No & 61 & 5.8 & 989 & 94.2 & 1050 & 64.6 & - \\
\hline \multirow[t]{2}{*}{ Liver cirrhosis } & Yes & 7 & 29.2 & 17 & 70.8 & 24 & 1.5 & $0.01^{c}$ \\
\hline & No & 178 & II.I & 1424 & 88.9 & 1602 & 98.5 & - \\
\hline \multirow[t]{2}{*}{ Hepatitis } & Yes & 2 & 18.2 & 9 & 81.8 & II & 4.9 & $1.0^{c}$ \\
\hline & No & 35 & 16.3 & 180 & 83.7 & 215 & 95.1 & - \\
\hline \multirow[t]{2}{*}{ Dementia } & Yes & 39 & 22.5 & 134 & 77.5 & 173 & 10.6 & $<0.001$ \\
\hline & No & 146 & 10.1 & 1307 & 90 & 1453 & 89.4 & - \\
\hline \multirow[t]{2}{*}{$\mathrm{CHF}$} & Yes & 85 & 28.8 & 210 & 71.2 & 295 & 18.1 & $<0.001$ \\
\hline & No & 100 & 7.5 & $|23|$ & 92.5 & $|33|$ & 81.9 & - \\
\hline \multirow[t]{2}{*}{ Cancer } & Yes & 14 & 20.6 & 54 & 79.4 & 68 & 4.2 & 0.02 \\
\hline & No & $17 \mid$ & II & 1387 & 89 & 1558 & 95.8 & - \\
\hline \multirow[t]{2}{*}{ Hypertension } & Yes & 143 & 13.9 & 889 & 86.1 & 1032 & 63.5 & $<0.001$ \\
\hline & No & 42 & 7.1 & 552 & 92.9 & 594 & 36.5 & - \\
\hline \multirow[t]{2}{*}{ TIA } & Yes & 25 & 16.2 & 129 & 83.8 & 154 & 9.5 & 0.046 \\
\hline & No & 160 & 10.9 & 1312 & 89.1 & 1472 & 90.5 & - \\
\hline \multirow[t]{2}{*}{ COPD } & Yes & 63 & 15.3 & 350 & 84.8 & 413 & 25.4 & 0.004 \\
\hline & No & 122 & 10.1 & 1091 & 89.9 & 1213 & 74.6 & - \\
\hline \multirow[t]{2}{*}{ Stroke } & Yes & 8 & 20.5 & 31 & 79.5 & 39 & 2.4 & $0.08^{c}$ \\
\hline & No & 177 & 11.2 & 1410 & 88.9 & 1587 & 97.6 & - \\
\hline Pulmonary embolism & Yes & 7 & 22.6 & 24 & 77.4 & 31 & 1.9 & $0.08^{c}$ \\
\hline & No & 178 & 11.2 & 1417 & 88.9 & 1595 & 98.1 & - \\
\hline Type 2 diabetes mellitus & Yes & 82 & 13.1 & 546 & 86.9 & 628 & 38.6 & 0.09 \\
\hline & No & 103 & 10.3 & 895 & 89.7 & 998 & 61.4 & - \\
\hline Lipid disorders & Yes & 71 & 13 & 474 & 87 & 545 & 33.5 & 0.14 \\
\hline & No & 114 & 10.6 & 967 & 89.5 & 1081 & 66.5 & - \\
\hline Tobacco dependence & Yes & 15 & 11.3 & 118 & 88.7 & 133 & 8.2 & 0.97 \\
\hline & No & 170 & 11.4 & 1323 & 88.6 & 1493 & 91.8 & - \\
\hline Alcohol dependence & Yes & 0 & 0 & 19 & 1.3 & 19 & 1.2 & $0.16^{\mathrm{c}}$ \\
\hline & No & 185 & 11.5 & 1422 & 98.7 & 1607 & 98.8 & - \\
\hline
\end{tabular}


Table I (Continued).

\begin{tabular}{|c|c|c|c|c|c|c|c|c|}
\hline & & \multicolumn{2}{|c|}{ Died $(n=185)$} & \multicolumn{2}{|c|}{ Survived $(n=|44|)$} & \multicolumn{2}{|c|}{ Total $(n=1626)$} & \multirow[t]{2}{*}{ p-value ${ }^{a}$} \\
\hline & & $\mathbf{n}$ & \% (Within Row) & $\mathbf{n}$ & \% (Within Row) & $\mathbf{n}$ & $\%$ (of Total) & \\
\hline \multirow[t]{2}{*}{ Opiate dependence } & Yes & 146 & 12.9 & 982 & 87.1 & 1128 & 69.4 & 0.003 \\
\hline & No & 39 & 7.8 & 459 & 92.2 & 498 & 30.6 & - \\
\hline \multirow[t]{2}{*}{ Remdesivir use } & Yes & 82 & 11.9 & 606 & 88.1 & 688 & 42.3 & 0.56 \\
\hline & No & 103 & 1 & 835 & 89 & 938 & 57.7 & - \\
\hline \multirow[t]{2}{*}{ Dexamethasone use } & Yes & 155 & 12.3 & 1103 & 87.7 & 1258 & 77.4 & 0.03 \\
\hline & No & 30 & 8.1 & 338 & 91.9 & 368 & 22.6 & - \\
\hline \multirow[t]{2}{*}{ ICU stay } & Yes & 61 & 27.1 & 164 & 72.9 & 225 & 13.8 & $<0.001$ \\
\hline & No & 124 & 8.9 & 1277 & 91.2 & $140 \mid$ & 86.2 & - \\
\hline \multirow[t]{4}{*}{ Length of stay (days) } & $<5$ & 43 & 8 & 494 & 92 & 537 & 33 & $<0.01$ \\
\hline & 5 to $<10$ & 45 & 7.4 & 563 & 92.6 & 608 & 37.4 & - \\
\hline & 10 to $<20$ & 56 & 18.1 & 254 & 81.9 & 310 & 19.1 & - \\
\hline & 20 and greater & $4 I$ & 24 & 130 & 76 & 171 & 10.5 & - \\
\hline \multirow[t]{3}{*}{ Insurance type } & Medicaid/ & 169 & 13.1 & 1125 & 86.9 & 1294 & 79.6 & $<0.001$ \\
\hline & Medicare & & & & & & & \\
\hline & Other $^{d}$ & 16 & 4.8 & 316 & 95.2 & 332 & 20.4 & - \\
\hline \multirow{2}{*}{$\begin{array}{l}\text { High erythrocyte } \\
\text { sedimentation rate }\end{array}$} & Yes & 36 & 15.1 & 202 & 84.9 & 238 & 74.6 & 0.24 \\
\hline & No & 8 & 9.9 & 73 & 90.1 & 81 & 25.4 & - \\
\hline \multirow[t]{2}{*}{ Pancytopenia } & Yes & 6 & 12.5 & 42 & 87.5 & 48 & 3 & 0.8 \\
\hline & No & 179 & 11.3 & 1399 & 88.7 & 1578 & 97.1 & - \\
\hline \multirow[t]{2}{*}{ Leucopenia } & Yes & 12 & II & 97 & 89 & 109 & 6.7 & 0.9 \\
\hline & No & 173 & 11.4 & 1344 & 88.6 & 1517 & 93.3 & - \\
\hline \multirow[t]{2}{*}{$C R P \geq 3.0 \mathrm{mg} / \mathrm{L}$} & Yes & 102 & 14.9 & 584 & 85.1 & 686 & 71.2 & $<0.001$ \\
\hline & No & 18 & 6.5 & 259 & 93.5 & 277 & 28.8 & - \\
\hline \multirow[t]{2}{*}{ High ferritin ${ }^{f}$} & Yes & 76 & 14.6 & 444 & 85.4 & 520 & 53.7 & 0.01 \\
\hline & No & 40 & 8.9 & 409 & 91.1 & 449 & 46.3 & - \\
\hline \multirow[t]{2}{*}{ Anemia } & Yes & 25 & 16.6 & 126 & 83.4 & $|5|$ & 9.3 & 0.04 \\
\hline & No & 160 & 10.9 & 1315 & 89.2 & 1475 & 90.7 & - \\
\hline \multirow[t]{2}{*}{$\mathrm{LDH} \geq 280 \mathrm{U} / \mathrm{L}$} & Yes & 75 & 18.9 & 322 & 81.1 & 397 & 46.3 & $<0.001$ \\
\hline & No & 27 & 5.9 & 434 & 94.1 & 461 & 53.7 & - \\
\hline \multirow[t]{2}{*}{ D-dimer $>0.5$} & Yes & 109 & 14.4 & 647 & 85.6 & 756 & 75.3 & $<0.001$ \\
\hline & No & 10 & 4 & 238 & 96 & 248 & 24.7 & - \\
\hline \multirow[t]{2}{*}{ Thrombocytopenia } & Yes & 36 & 20.3 & $14 \mid$ & 79.7 & 177 & 10.9 & $<0.001$ \\
\hline & No & 149 & 10.3 & 1300 & 89.7 & 1449 & 89.1 & - \\
\hline
\end{tabular}

Notes: ${ }^{a}$ Comparisons tested using Chi-square tests unless otherwise noted. Bolded $\mathrm{p}$-values are $<0.05$. ${ }^{\mathrm{b}}$ Comparison tested with ANOVA due to $>2$ groups. ${ }^{\mathrm{c}} \mathrm{Comparison}$ tested using Fishers exact test to adjust for small cell sizes. ${ }^{d}$ Combined for statistical purposes: agency, employee health insurance, commercial, self-pay, workers

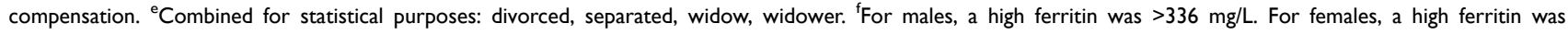
$>307 \mathrm{mg} / \mathrm{L}$. ${ }^{\mathrm{g}}$ For males, a high erythrocyte sedimentation rate was $>22 \mathrm{~mm} / \mathrm{hr}$. For females, a high erythrocyte sedimentation rate was $>29 \mathrm{~mm} / \mathrm{hr}$.

Abbreviations: BMI, body mass index; CKD, chronic kidney disease; ARF, acute respiratory failure; COPD, chronic obstructive pulmonary disease; TIA, transient ischemic attack; CRP, C-reactive protein; LDH, lactate dehydrogenase.

chronic obstructive pulmonary disease (COPD), acute respiratory failure (ARF), liver cirrhosis, chronic kidney disease (CKD), dementia, cancer, anemia, and opiate dependence. A multivariable logistic-regression model was developed. Independent predictors of in-hospital death and their corresponding odds ratios and $95 \%$ confidence intervals are shown in Table 2. At an age greater than 65 years, CHF, CKD, ARF, cancer, and intensive care unit (ICU) stay were associated with a higher risk of in-hospital death. In a sub-group of patients with biomarker data available, the results were similar. In this sub-group, dementia was associated with higher in-hospital mortality (OR 1.98, CI 1.04-3.78, p = 0.04). Patients with thrombocytopenia (OR 1.75, CI 1.01-3.05, p=0.047), and LDH levels $\geq 280 \mathrm{U} / \mathrm{L}$ (OR 3.28, CI 1.93-5.58, $\mathrm{p}<0.001$ ) were associated with higher in-hospital mortality. 
Table 2 Independent Predictors of In-Hospital Deaths from Multivariable Logistic-Regression Analysis in Patients Hospitalized with COVID-19

\begin{tabular}{|c|c|c|c|c|}
\hline \multicolumn{5}{|c|}{ Sub-Sample with Biomarkers $(n=858)^{a}$} \\
\hline Variable & OR & L95\% Cl & U95\% Cl & P-value \\
\hline Age (years) ${ }^{\mathrm{b}}$ & & & & 0.02 \\
\hline 18 to 49 & (ref) & - & - & - \\
\hline 50 to 64 & 1.05 & 0.31 & 3.6 & 0.93 \\
\hline 65 and older & 2.4 & 0.79 & 7.32 & 0.12 \\
\hline Congestive heart failure & 2.88 & 1.73 & 4.79 & $<0.001$ \\
\hline CKD & 3.06 & 1.78 & 5.23 & $<0.001$ \\
\hline ARF & 2.73 & 1.51 & 4.92 & 0.001 \\
\hline Dementia & 1.98 & 1.04 & 3.78 & 0.04 \\
\hline Cancer & 2.73 & 1.12 & 6.64 & 0.047 \\
\hline Thrombocytopenia & 1.75 & 1.01 & 3.05 & 0.047 \\
\hline $\mathrm{LDH} \geq 280 \mathrm{U} / \mathrm{L}$ & 3.28 & 1.93 & 5.58 & $<0.001$ \\
\hline Intercept & 0.004 & 0.001 & 0.02 & $<0.001$ \\
\hline \multicolumn{5}{|c|}{ Full Sample without Biomarkers $(n=1626)^{c}$} \\
\hline Variable & OR & L95\% Cl & U95\% Cl & P-value \\
\hline Age (years) & & & & $<0.001$ \\
\hline 18 to 49 & (ref) & - & - & - \\
\hline 50 to 64 & 1.69 & 0.61 & 4.66 & 0.31 \\
\hline 65 and older & 4.46 & 1.75 & 11.36 & 0.002 \\
\hline Congestive heart failure & 2.47 & 1.69 & 3.61 & $<0.001$ \\
\hline CKD & 2.19 & 1.51 & 3.19 & $<0.001$ \\
\hline Cancer & 2.3 & 1.13 & 4.69 & 0.02 \\
\hline ARF & 3.74 & 2.49 & 5.61 & $<0.001$ \\
\hline ICU & 1.98 & 1.31 & 3 & 0.001 \\
\hline Length of stay (days) & & & & 0.02 \\
\hline$<5$ & (ref) & - & - & - \\
\hline 5 to $<10$ & 0.56 & 0.34 & 0.91 & 0.02 \\
\hline 10 to $<20$ & 0.96 & 0.58 & 1.58 & 0.87 \\
\hline 20 and more & 1.2 & 0.68 & 2.14 & 0.53 \\
\hline Intercept & 0.01 & 0.003 & 0.02 & $<0.001$ \\
\hline
\end{tabular}

Notes: ${ }^{a}$ Random intercept variance estimate and $95 \% \mathrm{Cl}$ for facility: $0.25(0.02,2.75)$. Random intercept variance estimate and $95 \%$ $\mathrm{Cl}$ for month: $0.03(0.0002,5.28)$. ${ }^{b}$ Further combined for statistical analysis purposes. ${ }^{\mathrm{c}}$ Random intercept variance estimate and $95 \%$ $\mathrm{Cl}$ for facility: 0.08 (0.01, 0.72). Random intercept variance estimate and $95 \% \mathrm{Cl}$ for month: $0.12(0.02,0.56)$.

Abbreviations: CKD, chronic kidney disease; ARF, acute respiratory failure; LDH, lactate dehydrogenase; ICU, intensive care unit. 
Differences in mean length of stay by demographic characteristics, admission diagnoses, serum biomarkers, and treatments among patients hospitalized for COVID-19 are shown in Supplementary Table 1. Differences in patients with COVID-19 who were readmitted within 30 days of hospitalization versus those that were not readmitted are shown in $\underline{\text { Supplementary Table } 2}$ and differences among patients that were readmitted between 31 and 60 days after hospitalization versus those that were not readmitted are shown in Supplementary Table 3. The factors associated with length of stay (days) are shown in Supplementary Table 4. Factors associated with the odds of being readmitted in a sample of patients that survived the first hospitalization for COVID-19 are shown in Supplementary Table 5 for patients readmitted within 30 days and Supplementary Table 6 for patients readmitted between 31 and 61 days.

\section{Discussion}

Our research confirms previous reports of the independent relationship of older age, CHF, CKD, cancer, and ARF with COVID-19 mortality. Our results also suggest that patients with elevated LDH levels and/or thrombocytopenia are more likely to die of the infection. Neither harmful nor beneficial associations were noted for remdesivir or dexamethasone therapy.

It is well known that older people are at the highest risk of COVID-19 morbidity and mortality. ${ }^{13}$ It has been shown in previous studies that pre-existing conditions, such as cardiovascular disease, chronic kidney disease, chronic lung diseases, type 2 diabetes mellitus, hypertension, and obesity, are associated with increased risk of intubation and mortality. ${ }^{14-17}$ The lower platelet count has been reported to be a marker of poor prognosis, not only in COVID-19 patients but also in critically ill patients. ${ }^{18,19}$ The mechanism of thrombocytopenia in COVID-19 patients might be related to decreased production, increased consumption and destruction of platelets. ${ }^{20}$ Previous studies have shown that LDH level may be used as an important tool in determining prognosis in patients with COVID-19. ${ }^{21}$ Our study shows increased mortality with elevated LDH levels supporting this finding. Additional laboratory abnormalities, such as neutrophil-to-lymphocyte ratio, troponin-I, and abnormal liver function tests, have also been associated with increased mortality and adverse outcomes, which can be further explored in future studies. ${ }^{22-27}$

The impact of COVID-19 on rural communities is a significant contemporary health issue. In addition to the higher prevalence of diseases, the rural population face unique health problems. The prevalence of cigarette smoking, obesity, and physical inactivity is higher in non-metropolitan counties than in metropolitan counties. ${ }^{28}$ It is also known that ethnic minorities exhibit higher number of morbidities despite younger age due to disproportionate exposure to unscored risk factors including obesity, household overcrowding, air pollution, housing quality and adult skills deprivation. ${ }^{29}$ The aging population, multiple co-morbidities, and health-related behaviors make rural patients vulnerable to COVID-19. They also face greater transportation barriers to health care than their urban counterparts. ${ }^{30}$ Longer travel distances and higher costs related to transportation services limit health care utilization in this population. Limited health literacy and health insurance literacy in rural areas pose additional challenges in the ability to access, understand, and use information to make informed health decisions. ${ }^{31,32}$ Rural residents have lower incomes and lower rates of health insurance, which serves as another barrier to accessing healthcare resources. It is estimated that less than $10 \%$ of the health care workforce practice in rural settings. However, $14.8 \%$ (46.2 million persons) of the total US population reside in the $63.0 \%$ of counties that are classified as either micropolitan or noncore. ${ }^{33}$ In addition, there is a resurgence of diseases, such as coal workers' pneumoconiosis in the rural population. In central Appalachia (Kentucky, Virginia, West Virginia), 20.6\% of long-tenured miners have coal workers' pneumoconiosis. ${ }^{34}$ Differences in health-related behaviors, access to healthcare services, and environmental exposures can contribute to a greater COVID-19 mortality in rural communities.

Lastly, even though our data was prior to approval of the vaccine, per the CDC reports, COVID-19 vaccination coverage was lower in rural counties (38.9\%) than in urban counties $(45.7 \%)$. These disparities persisted among all age groups and by sex. A larger proportion of people in the most rural counties traveled for vaccination to nonadjacent counties (ie, farther from their county of residence) compared with persons in the most urban counties. ${ }^{35}$ This further highlights the health care disparities in rural communities due to lack of health insurance, education, access to health care and higher proportions of co-morbidities or disabilities. 


\section{Limitations}

This study has several limitations, most of which are inherent to the analysis of administrative databases. Since the data is collected based on administrative codes, it is not possible to establish whether a complication was present on admission or developed during the hospital stay. In addition, biomarker data were not available in all patients. It is likely that biomarkers were evaluated in sicker patients. In addition, remdesivir or dexamethasone therapy may have only been administered in patients with ARF. Lastly, our data were prior to the emergence of COVID-19 variants and prior to the approval of the vaccine. Despite these limitations, this study addresses a significant knowledge gap as a contemporary epidemiological study of COVID-19 in rural regions.

\section{Conclusions}

To the best of our knowledge, this is the largest COVID-19 hospitalization dataset to come exclusively from rural facilities. A better understanding of the disease in rural areas is crucial, given its heightened vulnerability to adverse outcomes, especially due to poor vaccination rates.

\section{Abbreviations}

ARF, acute respiratory failure; BMI, body mass index; CHF, congestive heart failure; ICU, intensive care unit; IRB, institutional review board; TIA, transient ischemic attack; COPD, chronic obstructive pulmonary disease; COVID-19, coronavirus disease 2019; CKD, chronic kidney disease.

\section{Data Sharing Statement}

The data used in this study can be made available to researchers collaborating with Appalachian Regional Healthcare under a research agreement. However, the data is not publicly available due to the need to preserve the privacy of patient health information. The data accessed complied with relevant data protection and privacy regulations.

\section{Funding}

There is no funding to report.

\section{Disclosure}

All authors report no conflicts of interest in this work and have reported that they have no relationships relevant to the contents of this paper to disclose.

\section{References}

1. Dong E, Du H, Gardner L. An interactive web-based dashboard to track COVID-19 in real time. Lancet Infect Dis. 2020;20(5):533-534. doi:10.1016/S1473-3099(20)30120-1

2. Garcia MC, Rossen LM, Bastian B, et al. Potentially excess deaths from the five leading causes of death in metropolitan and nonmetropolitan counties - United States, 2010-2017. MMWR Surveill Summ. 2019;68(10):1-11. doi:10.15585/mmwr.ss6810a1

3. Zhai Y, Santibanez TA, Kahn KE, Srivastav A, Walker TY, Singleton JA. Rural, urban, and suburban differences in influenza vaccination coverage among children. Vaccine. 2020;38(48):7596-7602. doi:10.1016/j.vaccine.2020.10.030

4. Dearinger AT. COVID-19 reveals emerging opportunities for rural public health. Am J Public Health. 2020;110(9):1277-1278. doi:10.2105/ AJPH.2020.305864

5. Kalichman S, Shkembi B, Hernandez D, Katner H, Thorson KR. Income inequality, HIV stigma, and preventing HIV disease progression in rural communities. Prevent Sci. 2019;20(7):1066-1073. doi:10.1007/s11121-019-01013-5

6. Henning-Smith C, Tuttle M, Kozhimannil KB. Unequal distribution of COVID-19 risk among rural residents by race and ethnicity. $J$ Rural Health. 2021;37(1):224-226. doi:10.1111/jrh.12463

7. Naidoo RN, Jeebhay MF. COVID-19: a new burden of respiratory disease among South African miners? Curr Opin Pulm Med. $2021 ; 27(2): 79-87$. doi:10.1097/MCP.0000000000000759

8. Resurgence of progressive massive fibrosis in coal miners - Eastern Kentucky. MMWR. 2019-04-08T03:32:11Z/ $2019 ; 2016$.

9. Dorn A, Cooney RE, Sabin ML. COVID-19 exacerbating inequalities in the US. Lancet. 2020;395(10232):1243-1244. doi:10.1016/S01406736(20)30893-X

10. Rosenblatt RA, Hart LG. Physicians and rural America. West J Med. 2000;173(5):348-351. doi:10.1136/ewjm.173.5.348

11. Karim SA, Chen H-F. Deaths from COVID-19 in rural, micropolitan, and metropolitan areas: a county-level comparison. $J$ Rural Health. 2021;37 (1):124-132. doi:10.1111/jrh.12533 
12. Jun JF. COVID-19 Stats: COVID-19 Incidence,* by Urban-Rural Classification(†) - United States, January 22-October 31, 2020(§). MMWR Morb Mortal Wkly Rep. 2020;69(46):1753. doi:10.15585/mmwr.mm6946a6

13. Cuadros DF, Branscum AJ, Mukandavire Z, Miller FD, MacKinnon N. Dynamics of the COVID-19 epidemic in urban and rural areas in the United States. Ann Epidemiol. 2021;59:16-20. doi:10.1016/j.annepidem.2021.04.007

14. Gallo Marin B, Aghagoli G, Lavine K, et al. Predictors of COVID-19 severity: a literature review. Rev Med Virol. 2021;31(1):1-10. doi:10.1002/ rmv.2146

15. Zhu Z, Cai T, Fan L, et al. Clinical value of immune-inflammatory parameters to assess the severity of coronavirus disease 2019. Int J Infect Dis. 2020;95:332-339. doi:10.1016/j.jijid.2020.04.041

16. Huang C, Wang Y, Li X, et al. Clinical features of patients infected with 2019 novel coronavirus in Wuhan, China. Lancet. 2020;395 (10223):497-506. doi:10.1016/s0140-6736(20)30183-5

17. Zhou F, Yu T, Du R, et al. Clinical course and risk factors for mortality of adult inpatients with COVID-19 in Wuhan, China: a retrospective cohort study. Lancet. 2020;395(10229):1054-1062. doi:10.1016/s0140-6736(20)30566-3

18. Thachil J, Warkentin TE. How do we approach thrombocytopenia in critically ill patients? Br J Haematol. 2017;177(1):27-38. doi:10.1111/ bjh. 14482

19. Hana C, Aboulenain S, Dewaswala N, Narendran V. Does thrombocytopenia truly correlate with COVID-19 severity? Blood. 2020;136:39-40. doi:10.1182/blood-2020-142440

20. Xu P, Zhou Q, Xu J. Mechanism of thrombocytopenia in COVID-19 patients. Ann Hematol. 2020;99(6):1205-1208. doi:10.1007/s00277-02004019-0

21. Henry BM, Aggarwal G, Wong J, et al. Lactate dehydrogenase levels predict coronavirus disease 2019 (COVID-19) severity and mortality: a pooled analysis. Am J Emerg Med. 2020;38(9):1722-1726. doi:10.1016/j.ajem.2020.05.073

22. Stawinski PM, Dziadkowiec KN, Al-Abbasi B, et al. Model of End-Stage Liver Disease (MELD) score as a predictor of in-hospital mortality in patients with COVID-19: a novel approach to a classic scoring system. Cureus. 2021;13(5):e15179-e15179. doi:10.7759/cureus.15179

23. Al Abbasi B, Torres P, Ramos-Tuarez F, et al. Cardiac Troponin-I and COVID-19: a prognostic tool for in-hospital mortality. Cardiol Res. 2020;11 (6):398-404. doi:10.14740/cr1159

24. Dziadkowiec KN, Stawinski PM, Dewaswala N, et al. S1133 MELD, MELD-Na, and MELD-albumin scores as predictors of mortality in patients with SARS-CoV-2: an uncanny relationship during troubling times. Off $J$ Am Coll Gastroenterol. 2020;4:115.

25. Martinez AC, Dewaswala N, Tuarez FR, et al. Validation of sofa score in critically ill patients with Covid-19. Chest. 2020;158(4):A613. doi:10.1016/j.chest.2020.08.577

26. Trojan J, Mollon P, Daniele B. Comparative efficacy of cabozantinib and ramucirumab after sorafenib for patients with advanced hepatocellular carcinoma and AFP $>=400$ NG/ML. Hepatology. 2020;72S1:131A-1159A. doi:10.1002/hep.31579

27. Yildiz H, Yombi JC, Castanares-Zapatero D. Validation of a risk score to predict patients at risk of critical illness with COVID-19. Infect Dis. 2021;53(1):78-80. doi:10.1080/23744235.2020.1823469

28. Matthews KA, Croft JB, Liu Y, et al. Health-related behaviors by urban-rural county classification - United States, 2013. MMWR Surveill Summ. 2017;66(5):1-8. doi:10.15585/mmwr.ss6605a1

29. Soltan MA, Varney J, Sutton B, et al. COVID-19 admission risk tools should include multiethnic age structures, multimorbidity and deprivation metrics for air pollution, household overcrowding, housing quality and adult skills. BMJ Open Respir Res. 2021;8(1):e000951. doi:10.1136/ bmjresp-2021-000951

30. Syed ST, Gerber BS, Sharp LK. Traveling towards disease: transportation barriers to health care access. J Community Health. 2013;38(5):976-993. doi:10.1007/s10900-013-9681-1

31. Ramos IN, Ramos KS, Boerner A, He Q, Tavera-Garcia MA. Culturally-tailored education programs to address health literacy deficits and pervasive health disparities among Hispanics in rural Shelbyville, Kentucky. J Community Med Health Educ. 2013;3(7):20475. doi:10.4172/21610711.1000250

32. Edward J, Thompson R, Jaramillo A. Availability of health insurance literacy resources fails to meet consumer needs in rural, Appalachian communities: implications for state medicaid waivers. $J$ Rural Health. 2021;37(3):526-536. doi:10.1111/jrh.12485

33. Ingram DD, Franco SJ. 2013 NCHS Urban-Rural Classification Scheme for Counties. US Department of Health and Human Services, Centers for Disease Control and Prevention, National Center for Health Statistics; 2014:1-73.

34. Blackley DJ, Halldin CN, Laney AS. Continued increase in prevalence of coal workers' pneumoconiosis in the United States, 1970-2017. Am J Public Health. 2018;108(9):1220-1222. doi:10.2105/ajph.2018.304517

35. Murthy BP, Sterrett N, Weller D, et al. Disparities in COVID-19 vaccination coverage between urban and rural counties - United States, December 14, 2020-April 10, 2021. MMWR Morb Mortal Wkly Rep. 2021;70(20):759-764. doi:10.15585/mmwr.mm7020e3

International Journal of General Medicine

Dovepress

\section{Publish your work in this journal}

The International Journal of General Medicine is an international, peer-reviewed open-access journal that focuses on general and internal medicine, pathogenesis, epidemiology, diagnosis, monitoring and treatment protocols. The journal is characterized by the rapid reporting of reviews, original research and clinical studies across all disease areas. The manuscript management system is completely online and includes a very quick and fair peer-review system, which is all easy to use. Visit http://www.dovepress.com/testimonials.php to read real quotes from published authors.

Submit your manuscript here: https://www.dovepress.com/international-journal-of-general-medicine-journal 